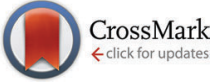

Cite this: Phys. Chem. Chem. Phys., 2015, 17, 32044

Received 14th October 2015, Accepted 9th November 2015

DOI: $10.1039 / c 5 c p 06166 k$

www.rsc.org/pccp

\title{
Effect of salts on the solubility of ionic liquids in water: experimental and electrolyte Perturbed-Chain Statistical Associating Fluid Theory $\dagger$
}

\author{
Catarina M. S. S. Neves, $\ddagger^{\mathrm{a}}$ Christoph Held,$\hbar^{*^{\mathrm{b}}}$ Sultan Mohammad, ${ }^{\mathrm{b}}$ Miko Schleinitz, \\ João A. P. Coutinho and Mara G. Freire*a
}

\begin{abstract}
Due to scarce available experimental data, as well as due to the absence of predictive models, the influence of salts on the solubility of ionic liquids (ILS) in water is still poorly understood. To this end, this work addresses the solubility of the IL 1-butyl-3-methylimidazolium bis(trifluoromethylsulfonyl)imide $\left(\left[\mathrm{C}_{4} \mathrm{C}_{1}\right.\right.$ im] $\left[\mathrm{NTf}_{2}\right]$ ), at $298.15 \mathrm{~K}$ and $0.1 \mathrm{MPa}$, in aqueous salt solutions (from 0.1 to $1.5 \mathrm{~mol} \mathrm{~kg}{ }^{-1}$ ). At salt molalities higher than $0.2 \mathrm{~mol} \mathrm{~kg}{ }^{-1}$, all salts caused salting-out of $\left[\mathrm{C}_{4} \mathrm{C}_{1} \mathrm{im}\right]\left[\mathrm{NTf}_{2}\right]$ from aqueous solution with their strength decreasing in the following order: $\mathrm{Al}_{2}\left(\mathrm{SO}_{4}\right)_{3}>\mathrm{ZnSO}_{4}>\mathrm{K}_{3} \mathrm{C}_{6} \mathrm{H}_{5} \mathrm{O}_{7}>\mathrm{KNaC}_{4} \mathrm{H}_{4} \mathrm{O}_{6}>$ $\mathrm{K}_{3} \mathrm{PO}_{4}>\mathrm{Mg}\left(\mathrm{CH}_{3} \mathrm{CO}_{2}\right)_{2}>\mathrm{K}_{2} \mathrm{HPO}_{4}>\mathrm{MgSO}_{4}>\mathrm{KH}_{2} \mathrm{PO}_{4}>\mathrm{KCH}_{3} \mathrm{CO}_{2}$. Some of these salts lead however to the salting-in of $\left[\mathrm{C}_{4} \mathrm{C}_{1}\right.$ im] $\left[\mathrm{NTf}_{2}\right]$ in aqueous medium at salt molalities lower than $0.2 \mathrm{~mol} \mathrm{~kg}^{-1}$. To attempt the development of a model able to describe the salt effects, comprising both the salting-in and salting-out phenomena observed, the electrolyte Perturbed-Chain Statistical Associating Fluid Theory (ePC-SAFT) was applied using ion-specific parameters. The gathered experimental data was modelled using ePC-SAFT parameters complemented by fitting a single binary parameter between $\mathrm{K}^{+}$and the $\mathrm{IL}$-ions to the IL solubility in $\mathrm{K}_{3} \mathrm{PO}_{4}$ aqueous solutions. Based on this approach, the description of anionspecific salting-out effects of the remaining potassium salts was found to be in good agreement with experimental data. Remarkably, ePC-SAFT is even able to predict the salting-in effect induced by $\mathrm{K}_{2} \mathrm{HPO}_{4}$, based on the single $\mathrm{K}^{+} / \mathrm{IL}$-ions binary parameter which was fitted to an exclusively salting-out effect promoted by $\mathrm{K}_{3} \mathrm{PO}_{4}$. Finally, ePC-SAFT was applied to predict the influence of other sodium salts on the $\left[\mathrm{C}_{4} \mathrm{C}_{1} \mathrm{im}\right]\left[\mathrm{NTf}_{2}\right]$ solubility in water, with experimental data taken from literature, leading to an excellent description of the liquid-liquid phase behaviour.
\end{abstract}

\section{Introduction}

The research relevance on ionic liquids (ILs) at both academic and industrial levels is undeniable. ${ }^{1} \mathrm{IL}$ applications in aqueous saline media have gained a significant attention in the past few years. $^{2-10}$ In particular, the preparation of IL-based aqueous biphasic systems (ABS), ${ }^{2}$ where the salt solution is used to control the solubility of hydrophilic ILs in water while allowing their recovery from aqueous effluents, ${ }^{2-4}$ or their use in the recovery

\footnotetext{
${ }^{a}$ CICECO - Aveiro Institute of Materials, Chemistry Department,

University of Aveiro, 3810-193 Aveiro, Portugal. E-mail: maragfreire@ua.pt

${ }^{b}$ Laboratory of Thermodynamics, Department of Biochemical and Chemical

Engineering, Technische Universitaet Dortmund, Emil-Figge-Str. 70, 44227 Dortmund, Germany.E-mail: christoph.held@bci.tu-dortmund.de

$\dagger$ Electronic supplementary information (ESI) available: Experimental solubility data in weight and molality units; ion speciation profile of $\mathrm{ZnSO}_{4}$ in aqueous solutions; ePC-SAFT parameters estimation for the citrate anion. See DOI: 10.1039/ c5cp06166k

\# Equally contributing authors.
}

of metals from leachates ${ }^{5,6}$ and to promote the separation and purification of the most diverse added-value products ${ }^{2,11-13}$ has become a hot topic of research in the last decade. In addition to the direct applications of IL-salt aqueous mixtures, the description and understanding of the ions specific effects and molecular-level mechanisms responsible for the two-phase formation or saltingin/-out phenomena have also been attempted..$^{7-9,14-17}$

In general, the availability of models for the description of the ILs solubility in aqueous saline solutions is very important for the design of separation and extraction processes. Currently, empirical or semi-empirical methods are used for the description of the liquid-liquid phase behaviour of systems involving ILs. When dealing with water-miscible ILs and the formation of ABS, the most common approach is the use of the correlation originally proposed by Merchuk et al. ${ }^{18}$ to describe the binodal/solubility curve of the ternary systems. This correlation was developed to describe experimental data of polymer-based systems, and it was successfully extended to ABS composed of ILs. ${ }^{2}$ This approach was latter modified by Zafarani-Moattar et al. ${ }^{19-21}$ in order to describe 
the temperature and $\mathrm{pH}$ effects on the binodal curve of each liquid-liquid system. More complex empirical correlations were also proposed in the past decade. ${ }^{22-30}$ To fully characterize these systems, tie-lines may be estimated based on the description of each binodal curve combined with a mass balance approach. ${ }^{18}$ The reliability of tie-lines is often assessed by the Othmer-Tobias ${ }^{31}$ and Bancroft ${ }^{25}$ equations. This mathematical procedure is appropriate for the accurate description of available experimental data, and thus valuable in engineering design for welldefined and known systems and conditions, but it has a limited extrapolation capability, i.e., it can hardly be extended towards other concentrations, temperatures or $\mathrm{pH}$ ranges, as well as to new systems composed of other ILs or salts.

A more general modelling with a sounder physical-chemical basis that explicitly accounts for molecular interactions between species is thus highly desirable, and where activity coefficient models fit within. Zafarani-Moattar and Hamzehzadeh ${ }^{20}$ applied modified NRTL and a modified Wilson model to describe the phase behaviour of ABS formed by ILs and an organic salt. With this approach, the authors ${ }^{20}$ could also describe the pH effects. The modified NRTL model required five $\mathrm{pH}$-independent adjustable parameters and four $\mathrm{pH}$-dependent parameters. ${ }^{20}$ By applying the Wilson model, the number of adjustable parameters was reduced to two $\mathrm{pH}$-independent parameters and four $\mathrm{pH}$-dependent parameters. Although explicitly accounting molecular interactions, these parameters cannot be transferred to other systems or other temperatures, thus making this approach as limited as the empirical approaches described above.

Equations of state (EoS) bear good prospects as predictive models. $^{32}$ Their parameterization, unlike those of activity coefficient models, is based on pure-component parameters which are valid independently of the mixture being considered. In addition, binary parameters might be used whenever necessary. These are usually transferable to higher (e.g. ternary) systems and are often temperature independent. Thus, EoS combine the advantages of requiring a very low number of binary parameters with the use of a small number of ready available (or easily estimable) purecomponent parameters. ${ }^{33}$ This opens the door for developing predictive models, which are becoming the preferred approaches in different research fields at both academia and industry. ${ }^{34}$ To the best of our knowledge, EoS have not been previously used for modelling complex water + salt + IL systems.

The use of ePC-SAFT (electrolyte Perturbed-Chain Statistical Associating Fluid Theory) to model phase equilibria of electrolyte systems can be considered highly promising. ${ }^{35-39}$ In order to apply ePC-SAFT to water + salt + IL systems both salts and ILs have to be characterized. For modelling inorganic salts with ePC-SAFT, ion-specific parameters are used. That is, modelling a salt solution requires pure-component parameters of the ions (e.g. $\left.\mathrm{Na}^{+}\right)$that are independent of the salt which they are part of (e.g. $\mathrm{NaCl}, \mathrm{NaNO}_{3}$ ). The newest strategy proposed ${ }^{35}$ allows describing also concentrated salt solutions by including dispersion effects between anions and cations. Different approaches have been proposed to characterize ILs using SAFT-based models. Among them, truncated PCP-SAFT (Perturbed-Chain Polar Statistical Associating Fluid Theory) ${ }^{40}$ was used assuming ILs as polar chain molecules. Using soft-SAFT, ${ }^{41}$ ILs were modelled as neutral chain molecules with association sites. Ji et al. $^{42}$ applied hetero-segmented SAFT to model densities of imidazolium-based ILs by considering them as molecules comprising a chain-like cation and a spherical anion, each having association sites. Also classical PC-SAFT has been applied to model thermodynamic properties of ILs. ${ }^{43-46}$ All these works neglected the Coulombic interactions of ILs or replaced them by association forces. In other recent works, ${ }^{47,48}$ it was shown that by considering Coulombic forces allowed the modelling of $\mathrm{IL}$ densities and gas solubility in ILs with higher accuracy compared to classical non-electrolyte PC-SAFT versions.

COSMO-RS (COnductor like Screening MOdel for Real Solvents $)^{49-51}$ already shown to be useful as a priori tool for the prediction of the phase equilibrium behaviour of systems comprising ILs. ${ }^{52-54}$ However, and although being of a predictive character, this model inherently requires previous quantum chemical calculations to obtain the sigma-profiles of the different solvents/solutes - a harder task when compared with the calculations needed to apply ePC-SAFT.

In this work, the solubility of $\left[\mathrm{C}_{4} \mathrm{C}_{1} \mathrm{im}\right]\left[\mathrm{NTf}_{2}\right]$ in aqueous solutions of 10 different salts (not previously investigated) was measured at salt concentrations ranging from ( 0 to 1.5 ) $\mathrm{mol} \mathrm{kg}^{-1}$, at $298.15 \mathrm{~K}$ and atmospheric pressure. The effects of the cation and anion of the added salt and respective salting-in/saltingout phenomena are discussed. The experimental data were finally modelled using ePC-SAFT aiming at evaluating the ability of this EoS to predict the salt influence on the solubility of ILs in aqueous media.

\section{Experimental}

\section{Materials}

The solubility measurements were performed for the IL 1-butyl3-methylimidazolium bis(trifluoromethylsulfonyl)imide, $\left[\mathrm{C}_{4} \mathrm{C}_{1} \mathrm{im}\right]$ $\left[\mathrm{NTf}_{2}\right]$, obtained from Iolitec with a purity of $99 \% \mathrm{w} / \mathrm{w}$, in aqueous solutions containing the following salts: potassium phosphate tribasic, $\mathrm{K}_{3} \mathrm{PO}_{4} \geq 98 \% \mathrm{w} / \mathrm{w}$ pure from Sigma-Aldrich; potassium phosphate dibasic, $\mathrm{K}_{2} \mathrm{HPO}_{4}>99 \% \mathrm{w} / \mathrm{w}$ pure from Riedel-de Haën; potassium phosphate monobasic, $\mathrm{KH}_{2} \mathrm{PO}_{4} \geq 99.5 \% \mathrm{w} / \mathrm{w}$ pure from Sigma-Aldrich; potassium acetate, $\mathrm{KCH}_{3} \mathrm{CO}_{2} \geq 99 \% \mathrm{w} / \mathrm{w}$ pure from Sigma-Aldrich; potassium citrate monohydrate, $\mathrm{K}_{3} \mathrm{C}_{6} \mathrm{H}_{5} \mathrm{O}_{7} \cdot \mathrm{H}_{2} \mathrm{O} \geq$ 99\% w/w pure from Sigma-Aldrich; potassium sodium tartrate tetrahydrate, $\mathrm{KNaC}_{4} \mathrm{H}_{4} \mathrm{O}_{6} \cdot 4 \mathrm{H}_{2} \mathrm{O} \geq 99 \% \mathrm{w} / \mathrm{w}$ pure from SigmaAldrich; magnesium sulphate heptahydrate, $\mathrm{MgSO}_{4} \cdot 7 \mathrm{H}_{2} \mathrm{O} \geq$ 98\% w/w pure from Panreac; magnesium acetate tetrahydrate, $\mathrm{Mg}\left(\mathrm{CH}_{3} \mathrm{CO}_{2}\right)_{2} \cdot 4 \mathrm{H}_{2} \mathrm{O} \geq 99.5 \% \mathrm{w} / \mathrm{w}$ pure from Sigma-Aldrich; zinc sulphate heptahydrate, $\mathrm{ZnSO}_{4} \cdot 7 \mathrm{H}_{2} \mathrm{O} \geq 99.5 \% \mathrm{w} / \mathrm{w}$ pure from Panreac; aluminium sulphate, $\mathrm{Al}_{2}\left(\mathrm{SO}_{4}\right)_{3} \cdot 18 \mathrm{H}_{2} \mathrm{O} \geq 98 \%$ w/w pure from Riedel de Häen. To reduce the water content and volatile impurities to negligible values, the IL was dried at vacuum and at $353 \mathrm{~K}$, using continuous stirring, for a minimum of $48 \mathrm{~h}$. After this procedure, the IL purity was checked by ${ }^{1} \mathrm{H},{ }^{13} \mathrm{C}$, and ${ }^{19} \mathrm{~F}$ NMR spectroscopy. The water used was double distilled, passed by a reverse osmosis system, and further treated with a Milli-Q plus 
185 water purification apparatus. It has a resistivity of $18.2 \mathrm{M} \Omega \mathrm{cm}$,

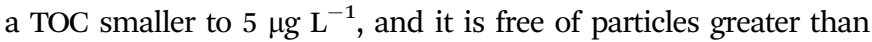
$0.22 \mu \mathrm{m}$.

\section{Solubility measurements}

The solubility of $\left[\mathrm{C}_{4} \mathrm{C}_{1} \mathrm{im}\right]\left[\mathrm{NTf}_{2}\right]$ in each aqueous salt solution (ranging from ( 0 to 1.5 ) $\mathrm{mol} \mathrm{kg}^{-1}$ ) was experimentally determined at $298.15 \mathrm{~K}$ and at atmospheric pressure. The exception was $\mathrm{Al}_{2}\left(\mathrm{SO}_{4}\right)_{3}$ that - due to its lower solubility in water - could only be studied from ( 0 to 0.75$) \mathrm{mol} \mathrm{kg}^{-1}$. For the hydrated salts the concentrations reported were calculated without the contribution of the water complexed with the salt. The aqueous salt solutions were prepared gravimetrically in ultrapure water within $\pm 10^{-4} \mathrm{~g}$. Both the IL and the aqueous salt phases were initially vigorously stirred and allowed to reach mutual saturation for at least $48 \mathrm{~h}$. This period was found to be the minimum time required to guarantee a complete separation of the two phases and to guarantee that no further variations in mole fraction solubilities occurred. ${ }^{55}$ The glass vials containing the two visible liquid phases were placed inside an aluminium block located in an isolated air bath capable of maintaining the temperature within $\pm 0.01 \mathrm{~K}$. The temperature control was achieved with a PID temperature controller driven by a calibrated Pt100 (class 1/10) temperature sensor inserted in the aluminium block. The solubility of the IL in the aqueous phase was determined by UV-spectroscopy using a SHIMADZU UV-1700 Pharma-Spec Spectrometer at a wavelength of $211 \mathrm{~nm}$ (using a calibration curve previously established and discounting for the salts absorbance whenever occurring). This wavelength was found to be the maximum UV absorption length for the studied imidazolium-based IL. The samples of the aqueous solutions were taken from the equilibrium vials using dry glass syringes at the same temperature as for the measurements. Samples of $\approx 0.5 \mathrm{~g}$ were taken and diluted by a factor of $\approx(1: 100$ to $1: 500)$ $(\mathrm{w} / \mathrm{w})$ in ultra-pure water. The solubility results reported are an average of at least five independent measurements.

\section{ePC-SAFT}

Theory. The ePC-SAFT equation of state was used for the modelling of the salt influence on the solubility of $\left[\mathrm{C}_{4} \mathrm{C}_{1} \mathrm{im}\right]\left[\mathrm{NTf}_{2}\right]$ in aqueous salt solutions. Within ePC-SAFT, the residual Helmholtz energy $a^{\text {res }}$ of the system is calculated according to eqn (1):

$$
a^{\text {res }}=a^{\text {hc }}+a^{\text {disp }}+a^{\text {assoc }}+a^{\text {ion }}
$$

The reference system in ePC-SAFT is the "hard-chain" fluid, which contributes with the Helmholtz-energy $a^{\text {hc }}$ to $a^{\text {res }}$ of the system. On top of that, perturbations due to short-range attractions are accounted for by dispersive van der Waals forces and by associative hydrogen-bonding forces, denoted with Helmholtz energy contributions, $a^{\text {disp }}$ and $a^{\text {assoc }}$, respectively. ${ }^{56,57}$ Compared to original PC-SAFT, ePC-SAFT ${ }^{35,58}$ also accounts for long-range interactions between charged components via the Debye-Hückel contribution to $a^{\text {res }}$, expressed by $a^{\text {ion }}$.

The thermodynamic description of one compound $i$ requires three pure-compound parameters: segment number $\left(m_{\mathrm{i}}^{\text {seg }}\right)$, segment diameter $\left(\sigma_{\mathrm{i}}\right)$ and dispersion-energy parameter $\left(u_{\mathrm{i}} / k_{\mathrm{B}}\right)$.
The compounds with association properties are described with two additional parameters: the association-energy parameter, $\varepsilon^{A_{\mathrm{i}} B_{\mathrm{i}}} / k_{\mathrm{B}}$, and the association-volume parameter, $k^{A_{\mathrm{i}} B_{\mathrm{i}}}$.

The segment diameter and dispersion-energy parameter in the mixture of compounds $i$ and $j$ are modelled by combining rules of Lorentz and Berthelot, corrected with the binary parameters $l_{i j}$ and $k_{i j}$ :

$$
\begin{gathered}
\sigma_{i j}=\frac{1}{2}\left(\sigma_{i}+\sigma_{j}\right)\left(1-l_{i j}\right) \\
u_{i j}=\sqrt{u_{i} u_{j}}\left(1-k_{i j}\right)
\end{gathered}
$$

The calculation of the solubility of $\left[\mathrm{C}_{4} \mathrm{C}_{1} \mathrm{im}\right]\left[\mathrm{NTf}_{2}\right]$ in each aqueous phase requires liquid-liquid equilibrium (LLE) conditions. In this context, the isofugacity criteria for each compound in the two liquid phases were used based on the fugacity $f_{\mathrm{i}}$ for each compound. For water, the following relationship was applied: ${ }^{59}$

$$
f_{\mathrm{i}}^{\mathrm{I}}=f_{\mathrm{i}}^{\mathrm{II}}
$$

For the salts and IL, the following relation was used:

$$
\left(f_{\text {an }}^{\mathrm{I}}\right)^{\nu_{\text {an }}} \cdot\left(f_{\text {cat }}^{\mathrm{I}}\right)^{\nu_{\text {cat }}}=\left(f_{\text {an }}^{\mathrm{II}}\right)^{\nu_{\text {an }}} \cdot\left(f_{\text {cat }}^{\mathrm{II}}\right)^{\nu_{\text {cat }}}
$$

where $\nu_{\text {an }}$ and $\nu_{\text {cat }}$ are the number of anions and cations in the IL and salts, respectively.

Modelling strategy and parameterization. Applying ePCSAFT to water + salt + IL systems requires the determination and knowledge of the pure compounds parameters. Water was described by a 2B two-site association model. ${ }^{60,61}$ This parameter set was chosen as it is specially suitable for biological solutions, and because the salt-ion parameters were fitted to data of aqueous solutions using the $2 \mathrm{~B}$ water parameter set. ${ }^{60,61}$ The association behaviour of water is explicitly accounted for, whereas all other compounds were treated as non-associative species. The salts and IL were considered as fully dissociated into cations and anions. For the IL, this approach was applied due to the very low solubility of the studied IL in aqueous media. At such low concentrations, complete dissociation can be assumed. Furthermore, the modelling of electrolyte solutions requires the dielectric constant of the solution. According to our previous work, ${ }^{35}$ the dielectric constant was taken as the value of pure water, i.e., 78.4 at $298.15 \mathrm{~K}$. This is a rough assumption, which is however necessary to apply the ePC-SAFT parameters for all ions considered in this work. The expression published by Cameretti et al. ${ }^{58}$ was used also in this work. For modelling $\left[\mathrm{C}_{4} \mathrm{C}_{1} \mathrm{im}\right]\left[\mathrm{NTf}_{2}\right]$ using ePC-SAFT, the IL was split into the two IL-ions $\left[\mathrm{C}_{4} \mathrm{C}_{1} \mathrm{im}\right]^{+}$and $\left[\mathrm{NTf}_{2}\right]^{-}$. The IL-ions were treated as non-polar non-associating chain-like species that were allowed to interact attractively via dispersion and Coulombic forces. The pure-component parameters of these IL-ions $\left(m_{\mathrm{i}}^{\mathrm{seg}}\right.$, $\left.\sigma, u_{\mathrm{i}} / k_{\mathrm{B}}\right)$ were fitted by Ji et $a .^{47}$ to pure-IL density data. The pure-component parameters for salt-ions were taken from Held et $a l .{ }^{35}$, except for the citrate anion $\left(\mathrm{C}_{6} \mathrm{H}_{5} \mathrm{O}_{7}{ }^{3-}\right)$. The salt-ions were modelled as spherical species with $m_{\mathrm{i}}^{\text {seg }}=1$, and dispersion interactions were allowed only between salt-ions of different charge. Dispersion forces between salt-ions/IL-ions, water/ IL-ions, and water/salt-ions were explicitly taken into account. 
Table 1 ePC-SAFT pure-compound parameters used in this work

\begin{tabular}{lllll}
\hline Compound & $\sigma_{\mathrm{i}}(\AA)$ & $m_{\mathrm{i}}^{\text {seg }}$ & $u_{\mathrm{i}} / \mathrm{k}_{\mathrm{B}}(\mathrm{k})$ & $k_{i j}$ with water \\
\hline $\mathrm{Water}^{a}$ & $2.7971^{61}$ & $1.2047^{61}$ & $353.95^{61}$ & - \\
{$\left[\mathrm{C}_{4} \mathrm{C}_{1} \mathrm{im}^{+}\right]^{+}$} & $3.6371^{47}$ & $2.4805^{47}$ & $218.144^{47}$ & -0.016 \\
{$\left[\mathrm{NTf}_{2}\right]^{-}$} & $3.7469^{47}$ & $6.0103^{47}$ & $375.65^{47}$ & -0.016 \\
$\mathrm{~K}^{+}{ }^{35}$ & $2.8232^{35}$ & $1.000^{35}$ & $230.00^{35}$ & $0.20^{35}$ \\
$\mathrm{Na}^{+}$ & $2.8232^{35}$ & $1.000^{35}$ & $230.00^{35}$ & $4.77 \times 10^{-435}$ \\
$\mathrm{NH}_{4}{ }^{+}$ & $3.5740^{35}$ & $1.000^{35}$ & $230.00^{35}$ & $0.064^{35}$ \\
$\mathrm{H}_{3} \mathrm{O}^{+}$ & $3.4654^{35}$ & $1.000^{35}$ & $500.00^{35}$ & $0.25^{35}$ \\
$\mathrm{Mg}^{2+}$ & $3.1327^{35}$ & $1.000^{35}$ & $1500.00^{35}$ & $-0.25^{35}$ \\
$\mathrm{Zn}^{2+}$ & $2.9798^{35}$ & $1.000^{35}$ & $1250.00^{35}$ & $-0.25^{35}$ \\
$\mathrm{Cl}^{-}$ & $2.7560^{35}$ & $1.000^{35}$ & $170.00^{35}$ & $-0.25^{35}$ \\
$\mathrm{NO}_{3}{ }^{-}$ & $3.2988^{35}$ & $1.000^{35}$ & $130.00^{35}$ & $0.098^{35}$ \\
$\mathrm{C}_{6} \mathrm{H}_{5} \mathrm{O}_{7}{ }^{3-}$ & 5.0991 & 1.000 & 258.99 & -0.25 \\
$\mathrm{HPO}_{4}{ }^{2-}$ & $2.1621^{35}$ & $1.000^{35}$ & $146.02^{35}$ & $0.25^{35}$ \\
$\mathrm{PO}_{4}{ }^{3-}$ & $2.5516^{35}$ & $1.000^{35}$ & $310.00^{35}$ & $-0.25^{35}$ \\
$\mathrm{CH}_{3} \mathrm{CO}_{2}{ }^{-}$ & $3.9328^{35}$ & $1.000^{35}$ & $150.00^{35}$ & $-0.23^{35}$ \\
$\mathrm{SO}_{4}{ }^{2-}$ & $3.2988^{35}$ & $1.000^{35}$ & $130.00^{35}$ & $0.25^{35}$ \\
$\mathrm{CO}_{3}{ }^{2-}$ & $2.4422^{35}$ & $1.000^{35}$ & $249.26^{35}$ & $-0.25^{35}$
\end{tabular}

${ }^{a}$ For water, the $2 \mathrm{~B}$ association approach with the parameters $\varepsilon^{A_{i} B_{i}} / k_{\mathrm{B}}=$ $2425.67 \mathrm{~K}$ and $k^{A_{i} B_{i}}=0.0451$ was used.

The parameters of $\mathrm{C}_{6} \mathrm{H}_{5} \mathrm{O}_{7}{ }^{3-}$ were fitted in this work to density data and osmotic coefficient data of aqueous potassium citrate solutions. The result is illustrated in the ESI. $\dagger$ The ePC-SAFT pure-compound parameters used in this work are listed in Table 1.

For modelling mixtures with EoS, binary interaction parameters are needed. The $k_{i j}$ between water and $\left[\mathrm{C}_{4} \mathrm{C}_{1} \mathrm{im}\right]\left[\mathrm{NTf}_{2}\right]$ was fitted to LLE data of that binary system at $298.15 \mathrm{~K}$. The $k_{i j}$ values between IL-cation and water as well as between IL-anion and water were considered to be identical. The $k_{i j}$ parameters between water and salt-ions as well as between these were taken from literature. ${ }^{35}$ All $k_{i j}$ values used in this work are listed in Tables 1 and 2. For modelling the LLE of the mixture water + salt + IL no further binary parameters were applied. Based on these parameters, the IL solubility in the pseudo-ternary mixture containing five species (water, IL-ions, salt-ions) was then predicted.

For the comparison between experimental and modelling results, ARD (average relative deviation) values were determined. The ARD between the experimental (exp.) and modelled (mod.) mass fraction of the IL, $w_{1}$, was evaluated according to:

$$
\mathrm{ARD}=100 \cdot \frac{1}{\mathrm{NP}} \sum_{l=1}^{\mathrm{NP}}\left|\left(1-\frac{w_{l}^{\text {mod. }}}{w_{l}^{\text {exp } .}}\right)\right|
$$

Table 2 Binary parameters $k_{i j}$ and $l_{i j}$ between ions for ePC-SAFT modelling used in this work. All other binary parameters were set to zero

\begin{tabular}{lrll}
\hline Pair & \multicolumn{1}{l}{$k_{i j}$} & Pair & $l_{i j}$ \\
\hline $\mathrm{Na}^{+}-\mathrm{Cl}^{-}$ & $0.317^{35}$ & $\mathrm{~K}^{+}-\left[\mathrm{NTf}_{2}\right]^{-}$ & 0.55 \\
$\mathrm{Na}^{+}-\mathrm{NO}_{3}{ }^{-}$ & $-0.300^{35}$ & $\mathrm{~K}^{+}-\left[\mathrm{C}_{4} \mathrm{C}_{1} \mathrm{im}\right]^{+}$ & 0.55 \\
$\mathrm{Na}^{+}-\mathrm{CO}_{3}{ }^{2-}$ & $-1.000^{35}$ & $\mathrm{Zn}^{2+}-\left[\mathrm{NTf}_{2}\right]^{-}$ & 0.12 \\
$\mathrm{H}_{3} \mathrm{O}^{+}-\mathrm{Cl}^{-}$ & $0.654^{35}$ & $\mathrm{Zn}^{2+}-\left[\mathrm{C}_{4} \mathrm{C}_{1} \mathrm{im}\right]^{+}$ & 0.12 \\
$\mathrm{NH}_{4}{ }^{+}-\mathrm{Cl}^{-}$ & $-0.566^{35}$ & $\mathrm{Mg}^{2+}-\left[\mathrm{NTf}_{2}\right]^{-}$ & - \\
$\mathrm{K}^{+}-\mathrm{CH}_{3} \mathrm{CO}_{2}{ }^{-}$ & $1.000^{35}$ & $\mathrm{Mg}^{2+}-\left[\mathrm{C}_{4} \mathrm{C}_{1} \mathrm{im}\right]^{+}$ & - \\
$\mathrm{K}^{+}-\mathrm{C}_{6} \mathrm{H}_{5} \mathrm{O}_{7}{ }^{3-}$ & 1.000 & & \\
$\mathrm{~K}^{+}-\mathrm{HPO}_{4}{ }^{2-}$ & $1.000^{35}$ & & \\
$\mathrm{~K}^{+}-\mathrm{PO}_{4}{ }^{3-}$ & $1.000^{35}$ & & \\
$\mathrm{Zn}^{2+}-\mathrm{SO}_{4}{ }^{2-}$ & $-0.446^{35}$ & & \\
$\mathrm{Mg}^{2+}-\mathrm{SO}_{4}{ }^{2-}$ & $-1.000^{35}$ & & \\
$\mathrm{Mg}^{2+}-\mathrm{CH}_{3} \mathrm{CO}_{2}{ }^{-}$ & $-0.998^{35}$ & &
\end{tabular}

where NP is the number of experimental points for each ILwater-salt mixture.

The ARD for the solubility of the investigated IL in the aqueous phase of the salt-free solution was found to be $1.93 \%$.

\section{Results and discussion}

\section{Experimental results}

The solubility of $\left[\mathrm{C}_{4} \mathrm{C}_{1} \mathrm{im}\right]\left[\mathrm{NTf}_{2}\right]$ in each salt solution in concentrations ranging from ( 0 to 1.5 ) $\mathrm{mol} \mathrm{kg}^{-1}$ was measured at $298.15 \mathrm{~K}$ and atmospheric pressure. The detailed measured solubility data and respective standard deviations, in weight fraction and molality units, are presented in the ESI. $\dagger$ The experimental results obtained are depicted in Fig. 1 and 2. For an easier interpretation, the data are separated by cation and anion effects (the respective graphical representation in weight fraction is reported in the ESI $\dagger$ ).

For some salts, namely $\mathrm{KH}_{2} \mathrm{PO}_{4}, \mathrm{~K}_{2} \mathrm{HPO}_{4}, \mathrm{Al}_{2}\left(\mathrm{SO}_{4}\right)_{3}$ and $\mathrm{Mg}\left(\mathrm{CH}_{3} \mathrm{CO}_{2}\right)_{2}$, a salting-in effect is observed for concentrations up to $0.20 \mathrm{~mol} \mathrm{~kg}{ }^{-1}$. Above this concentration, the salting-out effect occurs for all salts studied. Furthermore, the solubility of the IL decreases up to one order of magnitude for the higher salt concentrations studied. Upon salt addition at $1.5 \mathrm{~mol} \mathrm{~kg}^{-1}$, the solubility of the IL is strongly decreased by $\mathrm{ZnSO}_{4}$ while $\mathrm{KCH}_{3} \mathrm{CO}_{2}$ has the lowest impact. In summary, at $1.5 \mathrm{~mol} \mathrm{~kg}^{-1}$ of salt, the IL solubility decreases in the following order of salts: $\mathrm{ZnSO}_{4}>\mathrm{K}_{3} \mathrm{C}_{6} \mathrm{H}_{5} \mathrm{O}_{7}>\mathrm{KNaC}_{4} \mathrm{H}_{4} \mathrm{O}_{6}>\mathrm{K}_{3} \mathrm{PO}_{4}>\mathrm{Mg}\left(\mathrm{CH}_{3} \mathrm{CO}_{2}\right)_{2}>$ $\mathrm{K}_{2} \mathrm{HPO}_{4}>\mathrm{MgSO}_{4}>\mathrm{KH}_{2} \mathrm{PO}_{4}>\mathrm{KCH}_{3} \mathrm{CO}_{2}$. The salt $\mathrm{Al}_{2}\left(\mathrm{SO}_{4}\right)_{3}$ is not in this sequence as its solubility in water is much lower than this sequence refers to. Nevertheless, at $0.75 \mathrm{~mol} \mathrm{~kg}^{-1}, \mathrm{Al}_{2}\left(\mathrm{SO}_{4}\right)_{3}$ causes the strongest salting-out effect observed amongst all salts under investigation. In fact, the salting-out effect of this salt at $0.75 \mathrm{~mol} \mathrm{~kg}^{-1}$ is similar to that displayed by $\mathrm{KNaC}_{4} \mathrm{H}_{4} \mathrm{O}_{6}$ at $1.5 \mathrm{~mol} \mathrm{~kg}^{-1}$.

In addition to the salt-specific effects, also ion-specific effects can be observed from the experimental solubility data. In Fig. 1 and 2, the anion-specific (potassium salts) and cation-specific (acetates and sulphates) effects are illustrated. Fig. 1 shows that

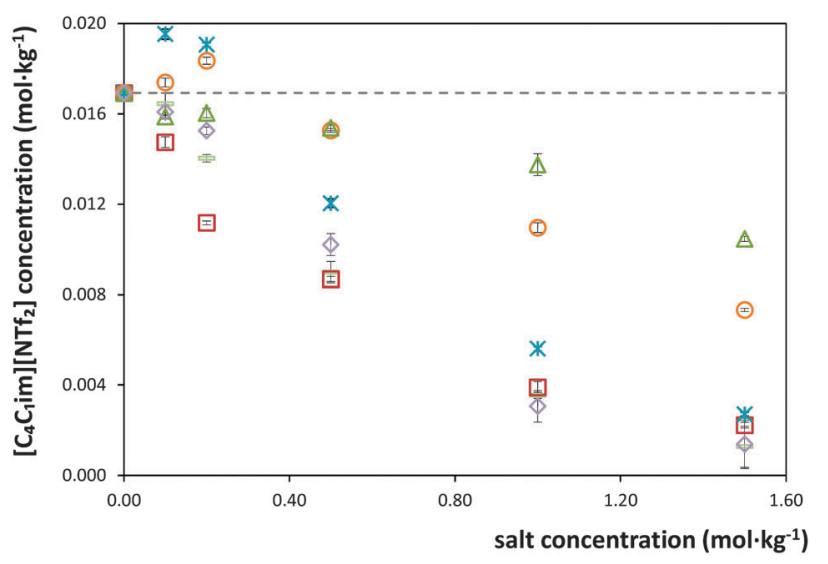

Fig. 1 Solubility of $\left[\mathrm{C}_{4} \mathrm{C}_{1}\right.$ im] $\left[\mathrm{NTf}_{2}\right]$ in water upon addition of potassium salts at $298.15 \mathrm{~K}$ with respective standard deviations:,$- \mathrm{K}_{3} \mathrm{C}_{6} \mathrm{H}_{5} \mathrm{O}_{7} ; \square$, $\mathrm{K}_{3} \mathrm{PO}_{4} ; *, \mathrm{~K}_{2} \mathrm{HPO}_{4} ; O, \mathrm{KH}_{2} \mathrm{PO}_{4} ; \triangle, \mathrm{KCH}_{3} \mathrm{CO}_{2} ; \diamond, \mathrm{KNaC}_{4} \mathrm{H}_{4} \mathrm{O}_{6}$. The dashed line is the reference value for the solubility of IL in pure water. 


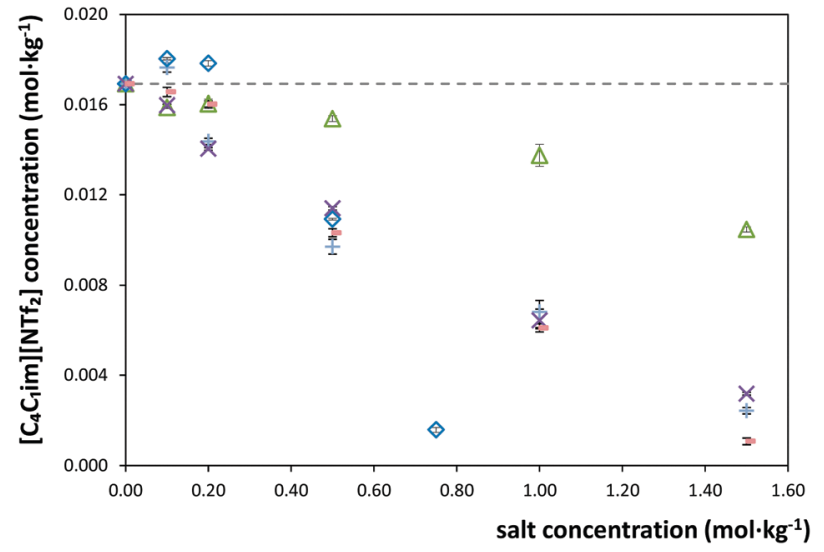

Fig. 2 Solubility of $\left[\mathrm{C}_{4} \mathrm{C}_{1}\right.$ im] $\left[\mathrm{NTf}_{2}\right]$ in water upon addition of sulphate and acetate salts at $298.15 \mathrm{~K}$ with respective standard deviations: $\diamond, \mathrm{Al}_{2}\left(\mathrm{SO}_{4}\right)_{3}$; $X, \mathrm{MgSO}_{4} ;-, \mathrm{ZnSO}_{4} ; \triangle, \mathrm{KCH}_{3} \mathrm{CO}_{2} ;+, \mathrm{Mg}\left(\mathrm{CH}_{3} \mathrm{CO}_{2}\right)_{2}$. The dashed line is the reference value for the solubility of $\mathrm{IL}$ in pure water.

potassium-based salts decrease the solubility of $\left[\mathrm{C}_{4} \mathrm{C}_{1} \mathrm{im}\right]\left[\mathrm{NTf}_{2}\right]$ in water with the exception of $\mathrm{K}_{2} \mathrm{HPO}_{4}$ and $\mathrm{KH}_{2} \mathrm{PO}_{4}$ at low concentrations $\left(<0.2 \mathrm{~mol} \mathrm{\textrm {kg } ^ { - 1 }}\right)$, for which a salting-in phenomenon is observed. This is analogous to what is typically observed considering proteins solubility in salt aqueous solutions. ${ }^{62}$ For the salts shown in Fig. 1, the salting-out strength observed at $1.5 \mathrm{~mol} \mathrm{~kg}^{-1}$ is according to: $\mathrm{KNaC}_{4} \mathrm{H}_{4} \mathrm{O}_{6} \approx \mathrm{K}_{3} \mathrm{C}_{6} \mathrm{H}_{5} \mathrm{O}_{7}>\mathrm{K}_{3} \mathrm{PO}_{4} \approx \mathrm{K}_{2} \mathrm{HPO}_{4} \gg \mathrm{KH}_{2} \mathrm{PO}_{4}>$ $\mathrm{KCH}_{3} \mathrm{CO}_{2}$. This order follows the Hofmeister series ${ }^{63}$ and can thus be considered an expected result; the same series was observed at the presence of sodium-based salts in a previous work. ${ }^{7}$

Fig. 2 presents the effect of sulphate- and acetate-based salts on the solubility of $\left[\mathrm{C}_{4} \mathrm{C}_{1} \mathrm{im}\right]\left[\mathrm{NTf}_{2}\right]$ in water. These effects might again be assumed ion-specific. However, combined with the anion $\mathrm{SO}_{4}{ }^{2-}$, the trivalent ion $\mathrm{Al}^{3+}$ induces a stronger salting-out than the divalent ions $\mathrm{Mg}^{2+}$ and $\mathrm{Zn}^{2+}$, followed by the monovalent $\mathrm{K}^{+}$. Therefore, the higher the cation's valence, the stronger the salting-out effect of the salt over the IL in aqueous media. This trend is in good agreement with previous results. ${ }^{7,14}$ Nevertheless, for these salts, the concentration-dependent speciation has a strong impact on their salting-out inducing abilities and should also be considered. ${ }^{64}$

\section{Predicting the salt influence on the IL solubility with ePC-SAFT: potassium, sulphate, and acetate salts}

Besides providing novel experimental data on the ILs solubility in salt aqueous solutions, another objective of this work consisted on the evaluation of the capability of ePC-SAFT to predict the experimental behaviour. For this purpose, in a first approach, the binary parameters $l_{i j}$ and $k_{i j}$ (eqn (2) and (3)) were set to zero, which led to deviations larger than $50 \%$ between experimental and ePC-SAFT predicted solubilities. These results were however expectable; previous works ${ }^{59,65}$ have shown that binary parameters between the compounds are required in order to quantitatively model solubilities or LLE with ePC-SAFT in ternary or higher order mixtures, such as the systems studied in the present work. Hence, several strategies were applied by introducing binary parameters between IL-ions and salt-ions. The aim of these strategies was to determine binary parameters which are ion-specific, and thus transferable to other IL-ion/salt-ion combinations. This means that, for example, the binary parameter between $\mathrm{K}^{+}$and IL-ion is valid for all potassium salts (i.e., for $\mathrm{K}_{3} \mathrm{PO}_{4}$ as well as for $\mathrm{KCH}_{3} \mathrm{CO}_{2}$ ). This approach allows semi-predictions as well as reducing the number of parameters used. To further reduce the number of binary parameters, the binary parameter between $\mathrm{K}^{+}$ and IL-cation was set equal to the binary parameter between $\mathrm{K}^{+}$ and the IL-anion. Among the strategies considered, it was found that these criteria could only be fulfilled by: (i) applying an ionspecific approach for the IL; (ii) using the pure-component parameters for the salt-ions proposed by Held et $a l^{35}$ and reported in Table 2 ; and (iii) using the binary parameter $l_{i j}$ instead of $k_{i j}$ in eqn (2). The binary parameter $l_{i j}$ between $\mathrm{K}^{+}$and IL-ion was fitted to the solubility of $\left[\mathrm{C}_{4} \mathrm{C}_{1} \mathrm{im}\right]\left[\mathrm{NTf}_{2}\right]$ in $\mathrm{K}_{3} \mathrm{PO}_{4}$ solutions using the data shown in Fig. 1. This parameter is listed in Table 2. This procedure was found to be required for $\mathrm{K}^{+}$and $\mathrm{Zn}^{2+}$. In contrast, all binary parameters between pairs of salt-anion/IL-ion were set to zero, as well as between $\mathrm{Mg}^{2+}$ and IL-ions.

The optimal strategy developed requires a maximum of one binary parameter between a salt-cation and the IL-ions. The results using this strategy are illustrated in Fig. 3 and 4. Fig. 3 shows that fitting the binary parameter $l_{i j}$ between $\mathrm{K}^{+}$and IL-ions to the data of $\mathrm{IL}$ solubility in $\mathrm{K}_{3} \mathrm{PO}_{4}$ solutions yields a quantitative description of the experimental salt-induced solubility of the IL. This is a promising result keeping in mind that usually several binary parameters are required to model the LLE of inorganic salt-containing or IL-containing mixtures. For instance, a recent work $^{20}$ used up to 9 binary parameters to correlate the LLE behaviour of water/IL/salt systems. Even more promising, the availability of an ion-specific model, such as ePC-SAFT, allows the development of transferable binary parameters. In this line, the fitted $l_{i j}$ parameter between $\mathrm{K}^{+}$and IL-ions was further applied to predict the solubility of potassium-based salts other than the $\mathrm{K}_{3} \mathrm{PO}_{4}$ used for fitting the $l_{i j}$. The results are illustrated in Fig. 3 for systems with $\mathrm{KCH}_{3} \mathrm{CO}_{2}, \mathrm{~K}_{3} \mathrm{C}_{6} \mathrm{H}_{5} \mathrm{O}_{7}$, and $\mathrm{K}_{2} \mathrm{HPO}_{4}$. Applying ePC-SAFT and the binary parameter $l_{i j}$ for $\mathrm{K}^{+} / \mathrm{IL}$-ions

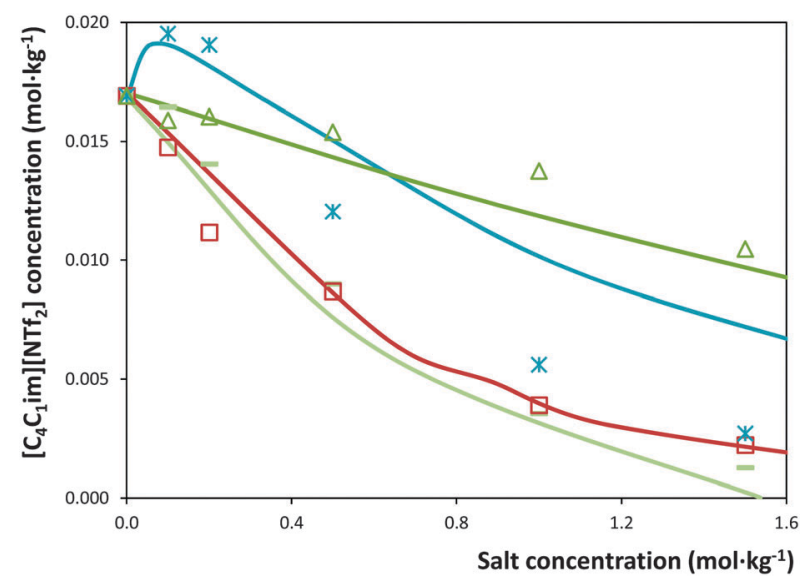

Fig. 3 Solubility of $\left[\mathrm{C}_{4} \mathrm{C}_{1}\right.$ im] $\left[\mathrm{NTf}_{2}\right]$ in water upon addition of potassiumbased salts at $298.15 \mathrm{~K}:-, \mathrm{K}_{3} \mathrm{C}_{6} \mathrm{H}_{5} \mathrm{O}_{7} ; \square, \mathrm{K}_{3} \mathrm{PO}_{4} ; *, \mathrm{~K}_{2} \mathrm{HPO}_{4} ; \triangle$, $\mathrm{KCH}_{3} \mathrm{CO}_{2}$. The lines represent modelling results with ePC-SAFT using parameters from Tables 1 and 2 . 


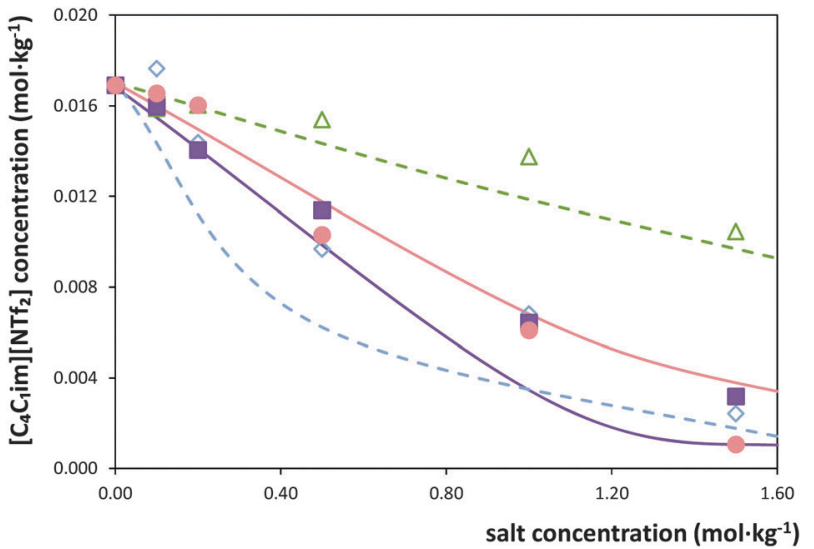

Fig. 4 Solubility of $\left[\mathrm{C}_{4} \mathrm{C}_{1}\right.$ im] $\left[\mathrm{NTf}_{2}\right]$ in water upon addition of acetatebased salts and sulphate-based salts at $298.15 \mathrm{~K}: \diamond,(--), \mathrm{Mg}\left(\mathrm{CH}_{3} \mathrm{CO}_{2}\right)_{2}$; $\triangle$, (--), $\mathrm{KCH}_{3} \mathrm{CO}_{2} ; \mathrm{O}^{\prime}(-) \mathrm{ZnSO}_{4} ; \square,(-) \mathrm{MgSO}_{4}$. The lines represent modelling results with ePC-SAFT using parameters from Tables 1 and 2 .

fitted to the solubility data of the water $/ \mathrm{IL} / \mathrm{K}_{3} \mathrm{PO}_{4}$ system allows predicting the salting-out of the IL from the aqueous phase with good agreement to the experimental observations. This is a quite good result, as these are modelling predictions; i.e., these data were neither used to fit the binary $l_{i j}$ parameter nor any purecomponent parameters. This statement might seemed weakened by the fact that the binary parameter was fitted to the system containing $\mathrm{K}_{3} \mathrm{PO}_{4}$, which induces salting-out in the whole saltconcentration range, thus showing the same influence upon the IL solubility as the salts $\mathrm{KCH}_{3} \mathrm{CO}_{2}$ and $\mathrm{K}_{3} \mathrm{C}_{6} \mathrm{H}_{5} \mathrm{O}_{7}$. Nevertheless, using the $l_{i j}$ parameter, ePC-SAFT is also able to correctly predict the influence of $\mathrm{K}_{2} \mathrm{HPO}_{4}$ on the IL solubility, including the salting-in region and the solubility maximum at $0.1 \mathrm{~mol} \mathrm{~kg}^{-1}$ experimentally observed. This is one of the most remarkable achievements as the binary parameter was fitted to a system containing $\mathrm{K}_{3} \mathrm{PO}_{4}$, which induces only salting-out along all the concentrations studied. To the best of our knowledge, a thermodynamic model or an equation of state were never used and demonstrated to be able to describe these remarkable type of results (salting-in $v s$. salting-out).

Fig. 4 shows the influence of sulphate-based salts and acetate-based salts on the solubility of $\left[\mathrm{C}_{4} \mathrm{C}_{1} \mathrm{im}\right]\left[\mathrm{NTf}_{2}\right]$ in aqueous solutions. All these salts induce a salting-out of the IL from the aqueous (IL-poor) phase. As shown in Fig. 4, ePC-SAFT can reproduce adequately the IL solubility in the different salt solutions. ePC-SAFT correctly predicts the salting-out ability strength for all salts with the exception for $\mathrm{ZnSO}_{4}$, for which a binary parameter $l_{i j} \mathrm{Zn}^{2+} / \mathrm{IL}$-ion had to be fitted to the experimental data. This limitation should be related with the $\mathrm{ZnSO}_{4}$ speciation ${ }^{64}$ that cannot be captured by the modelling approach used in this work. The species distribution of $\mathrm{ZnSO}_{4}$ in aqueous solution is highly complex and strongly depends on the salt concentration - $c f$. the ESI. $\dagger$ In order to describe this solution (and the salt-dependent IL solubility) adequately, the ePC-SAFT parameters for all species that will form (including the ion pairs) are required. However, this was outside the scope of this work as it would introduce additional binary parameters as well.
Predicting the salt influence on IL solubility with ePC-SAFT: chloride, nitrate, and carbonate salts

The previous results showed that one binary $l_{i j}$ parameter between $\mathrm{K}^{+}$and IL-ions, as well as between $\mathrm{Zn}^{2+}$ and IL-ions, are required in order to achieve a good description of the experimental data. Still, it must be stressed out that binary parameters between all other salt-ion/IL-ion pairs were set to zero and that the $\mathrm{K}^{+}-\mathrm{IL}$ binary $l_{i j}$ parameters were shown to be transferable to different potassium-based salts.

Encouraged by these promising results, ePC-SAFT was further applied as a fully predictive model to describe the salt influence on the $\left[\mathrm{C}_{4} \mathrm{C}_{1} \mathrm{im}\right]\left[\mathrm{NTf}_{2}\right]$ solubility in presence of a broad plethora of salts. Using the pure-component parameters for water, IL-ions, and salt-ions, the effect of the salt concentration upon the $\left[\mathrm{C}_{4} \mathrm{C}_{1} \mathrm{im}\right]\left[\mathrm{NTf}_{2}\right]$ solubility in aqueous solutions of sodium- and chloride-based salts was further predicted and compared to experimental literature data. ${ }^{7}$ The objective of this attempt was the validation of the predictive capability of ePCSAFT to describe ion-specific salting-out/-in effects.

Fig. 5 shows the experimental solubilities of $\left[\mathrm{C}_{4} \mathrm{C}_{1} \mathrm{im}\right]\left[\mathrm{NTf}_{2}\right]$ in aqueous salt solutions and the predictions achieved with ePC-SAFT. The impact of chloride-based salts on the solubility
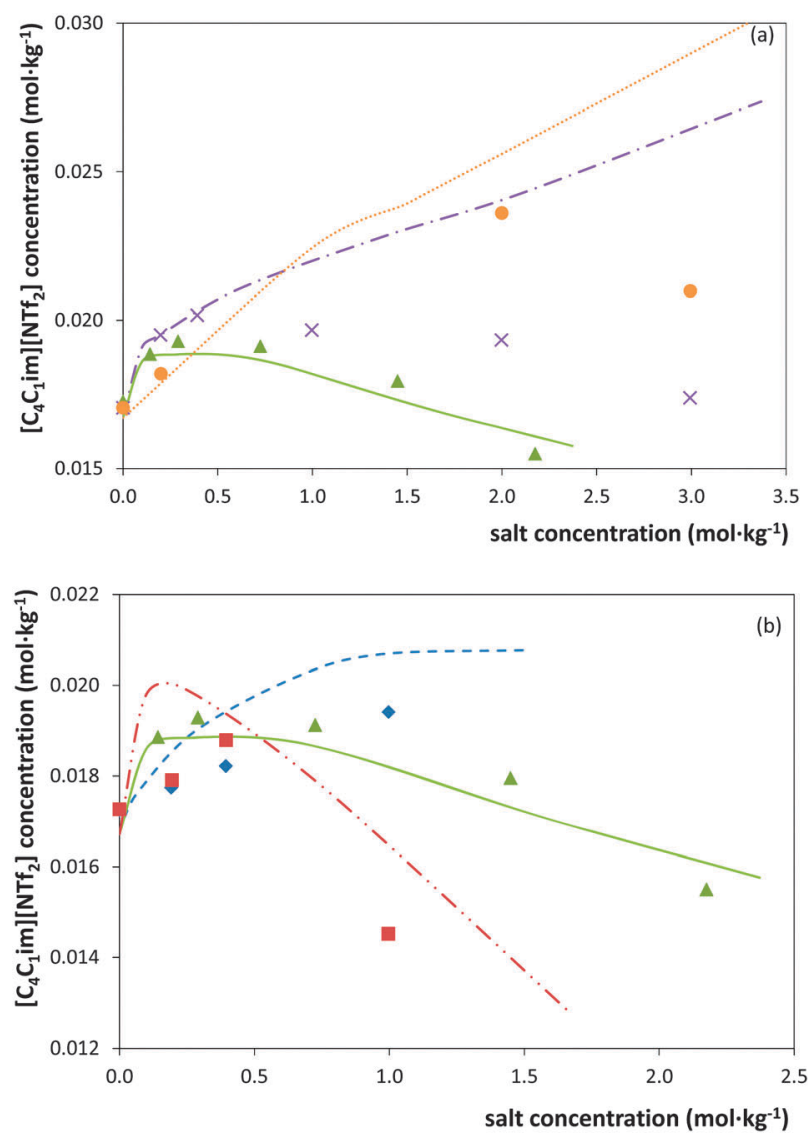

Fig. 5 Solubility of $\left[\mathrm{C}_{4} \mathrm{C}_{1}\right.$ im] $\left[\mathrm{NTf} \mathrm{f}_{2}\right]$ in water upon addition of (a) chloride and (b) sodium salts at $298.15 \mathrm{~K}$. Symbols represent the experimental data taken from literature, ${ }^{7}$ and lines represent predictions with ePC-SAFT using parameters from Tables 1 and 2: $\mathbf{A},(-), \mathrm{NaCl}_{i} \times,(--), \mathrm{NH}_{4} \mathrm{Cl} ; \mathbf{O},(\cdots)$, $\mathrm{HCl} ;,(--), \mathrm{NaNO}_{3} ; \square,(-.--), \mathrm{Na}_{2} \mathrm{CO}_{3}$. 
of $\left[\mathrm{C}_{4} \mathrm{C}_{1} \mathrm{im}\right]\left[\mathrm{NTf}_{2}\right]$ is depicted in Fig. 5a. Below a salt molality of $0.75 \mathrm{~mol} \mathrm{~kg}^{-1}$, all salts induce a salting-in of the IL, while $\mathrm{NaCl}$ induces a salting-out at molalities higher than $1.5 \mathrm{~mol} \mathrm{~kg}{ }^{-1}$.

Fig. 5b shows the influence of sodium-based salts on the solubility of $\left[\mathrm{C}_{4} \mathrm{C}_{1} \mathrm{im}\right]\left[\mathrm{NTf}_{2}\right]$. A salting-in phenomenon is observed for $\mathrm{NaCl}$ and $\mathrm{Na}_{2} \mathrm{CO}_{3}$ at low salt concentrations, followed by a saltingout at higher salt concentrations. In contrast, $\mathrm{NaNO}_{3}$ acts as a salting-in inducing salt in the entire salt concentration region. The strength of the salting-in of $\mathrm{NaCl}$ and $\mathrm{Na}_{2} \mathrm{CO}_{3}$ at low salt concentrations is very similar; however, $\mathrm{Na}_{2} \mathrm{CO}_{3}$ causes a stronger salting-out at higher salt concentrations. The molecular mechanism behind these salting-in/-out effects was established in a previous work. ${ }^{7}$

The experimental behaviour of the six systems described above is highly non-linear, unlike observed for many other molecules that follow a much simpler behaviour typically described using Setschenow coefficients. ${ }^{66}$ In Fig. 5, the predictive ePC-SAFT modelling results are compared with the experimental data for these systems. It must be again stressed out that neither purecompound nor binary interaction parameters were fitted to data of the ternary water $/\left[\mathrm{C}_{4} \mathrm{C}_{1} \mathrm{im}\right]\left[\mathrm{NTf}_{2}\right] /$ salt specific systems. The salting-in/-out effects of $\mathrm{NaCl}$ and $\mathrm{Na}_{2} \mathrm{CO}_{3}$ are predicted in good agreement with the experimental data. Also the stronger saltingout effect of $\mathrm{Na}_{2} \mathrm{CO}_{3}$ at higher salt concentrations is correctly predicted by ePC-SAFT. The model also correctly predicts the salting-out effect of the chloride salts upon the $\left[\mathrm{C}_{4} \mathrm{C}_{1} \mathrm{im}\right]\left[\mathrm{NTf}_{2}\right]$ solubility. In summary, this prediction capacity of ePC-SAFT is remarkable given the complexity of the systems studied, with four ions in solution, and the highly non-linear behaviour of $\left[\mathrm{C}_{4} \mathrm{C}_{1} \mathrm{im}\right]\left[\mathrm{NTf}_{2}\right]$ solubility in aqueous salt solutions.

In order to classify the results of the ePC-SAFT predictions, it should be noted that semi-empirical approaches using activity coefficient models, such as NRTL, require a large number of binary parameters. These allow correlating the behaviour of such complex systems. This work shows that the LLE behaviour of different $\left[\mathrm{C}_{4} \mathrm{C}_{1} \mathrm{im}\right]\left[\mathrm{NTf}_{2}\right]$-salt-water systems can be captured with ePC-SAFT in a predictive way, using only pure-compound parameters and ion-specific binary interaction parameters that are universally valid and ion-independent.

\section{Conclusions}

In this work, novel solubility data of the $\mathrm{IL}\left[\mathrm{C}_{4} \mathrm{C}_{1} \mathrm{im}\right]\left[\mathrm{NTf}_{2}\right]$ in aqueous solutions of ten different salts at molalities up to $1.5 \mathrm{~mol} \mathrm{~kg}{ }^{-1}$, at 298.15 $\mathrm{K}$ and 1 bar, were determined. The salting-out of the IL from aqueous media was observed at salt molalities higher than $0.20 \mathrm{~mol} \mathrm{~kg}^{-1}$. At the fixed molality of $1.5 \mathrm{~mol} \mathrm{~kg}^{-1}$ of salt, the strength of the salting-out effect decreases in the order: $\mathrm{ZnSO}_{4}>$ $\mathrm{K}_{3} \mathrm{C}_{6} \mathrm{H}_{5} \mathrm{O}_{7}>\mathrm{KNaC}_{4} \mathrm{H}_{4} \mathrm{O}_{6}>\mathrm{K}_{3} \mathrm{PO}_{4}>\mathrm{Mg}\left(\mathrm{CH}_{3} \mathrm{CO}_{2}\right)_{2}>\mathrm{K}_{2} \mathrm{HPO}_{4}>$ $\mathrm{MgSO}_{4}>\mathrm{KH}_{2} \mathrm{PO}_{4}>\mathrm{KCH}_{3} \mathrm{CO}_{2}$. The $\mathrm{Al}_{2}\left(\mathrm{SO}_{4}\right)_{3}$ salt at $0.75 \mathrm{~mol} \mathrm{~kg}^{-1}$, close to its saturation solubility in water, causes the strongest salting-out effect observed. Salts composed of cations with a higher valence are stronger salting-out agents. Some salts $\left(\mathrm{KH}_{2} \mathrm{PO}_{4}, \mathrm{~K}_{2} \mathrm{HPO}_{4}, \mathrm{Al}_{2}\left(\mathrm{SO}_{4}\right)_{3}\right.$ and $\left.\mathrm{Mg}\left(\mathrm{CH}_{3} \mathrm{CO}_{2}\right)_{2}\right)$ also induce the salting-in of the IL at salt molalities lower than $0.20 \mathrm{~mol} \mathrm{~kg}^{-1}$.
The measured experimental data were further described with ePC-SAFT, for which ion-specific ePC-SAFT parameters were used to describe the salts and the IL. A single binary parameter between $\mathrm{K}^{+}$and the IL-ions was fitted to solubility data of the IL in $\mathrm{K}_{3} \mathrm{PO}_{4}$ aqueous solutions. Further, this binary parameter was applied to predict the influence of potassiumbased salts on the solubility of the IL, and a good prediction was found. ePC-SAFT was even shown to be able to predict the salting-in induced by e.g., $\mathrm{K}_{2} \mathrm{HPO}_{4}$. This is a remarkable result as the binary parameter between $\mathrm{K}^{+} / \mathrm{IL}$-ions was fitted to solubility data in $\mathrm{K}_{3} \mathrm{PO}_{4}$ solution, which only induces the IL salting-out.

Finally, ePC-SAFT was applied to fully predict the influence of sodium- and chloride-based salts on the IL solubility in aqueous media. A good accuracy was found when compared with the experimental data taken from literature. Remarkably, both salting-in/-out effects were predicted.

In contrast to ePC-SAFT, semi-empirical approaches require a much higher number of binary parameters in order to correlate the behaviour of complex systems, such as IL-salt-water systems. This work shows that the solubility behaviour of ILs in aqueous solutions could be captured with ePC-SAFT in a predictive way, using only pure-compound parameters and ion-specific binary interaction parameters that are universally valid and independent of the ions in solution. To the best of our knowledge, such type of results has never previously been achieved using a thermodynamic model, while using a single equation of state.

\section{Acknowledgements}

The authors acknowledge the collaboration of Leila S. C. Rato and Michael Santos Silva for determining some of the experimental data. This work was developed in the scope of the project CICECO-Aveiro Institute of Materials (Ref. FCT UID/ CTM/50011/2013), financed by national funds through the FCT/ MEC and co-financed by FEDER under the PT2020 Partnership Agreement. Catarina M. S. S. Neves also acknowledges FCT for the postdoctoral grant SFRH/BPD/109057/2015. The research leading to reported results has received funding from the European Research Council under the European Union's Seventh Framework Programme (FP7/2007-2013)/ERC grant agreement no. 337753. The authors gratefully acknowledge the financial support of the IGFproject $17114 \mathrm{~N} / 1$ of the DECHEMA e.V. that was funded by the Federal Ministry of Economics and Technology (grant no. 005-10090053) based on an enactment of the German Federal Parliament (BMWi). The project was supported within the program "Promoting the Industrial Collective Research (IGF)" with the help of the German Federation of Industrial Research Associations (AiF).

\section{References}

1 N. V. Plechkova and K. R. Seddon, Chem. Soc. Rev., 2008, 37, 123-150.

2 M. G. Freire, A. F. M. Cláudio, J. M. M. Araújo, J. A. P. Coutinho, I. M. Marrucho, J. N. Canongia Lopes and L. P. N. Rebelo, Chem. Soc. Rev., 2012, 41, 4966-4995. 
3 C. M. S. S. Neves, M. G. Freire and J. A. P. Coutinho, $R S C$ Adv., 2012, 2, 10882-10890.

4 K. E. Gutowski, G. A. Broker, H. D. Willauer, J. G. Huddleston, R. P. Swatloski, J. D. Holbrey and R. D. Rogers, J. Am. Chem. Soc., 2003, 125, 6632-6633.

5 K. Binnemans, P. T. Jones, B. Blanpain, T. Van Gerven, Y. Yang, A. Walton and M. Buchert, J. Cleaner Prod., 2013, 51, 1-22.

6 N. Papaiconomou, G. Vite, N. Goujon, J.-M. Lévêque and I. Billard, Green Chem., 2012, 14, 2050-2056.

7 M. G. Freire, P. J. Carvalho, A. M. S. Silva, L. M. N. B. F. Santos, L. P. N. Rebelo, I. M. Marrucho and J. A. P. Coutinho, J. Phys. Chem. B, 2009, 113, 202-211.

8 M. G. Freire, C. M. S. S. Neves, A. M. S. Silva, L. M. N. B. F. Santos, I. M. Marrucho, L. P. N. Rebelo, J. K. Shah, E. J. Maginn and J. A. P. Coutinho, J. Phys. Chem. B, 2010, 114, 2004-2014.

9 L. I. N. Tome, F. R. Varanda, M. G. Freire, I. M. Marrucho and J. A. P. Coutinho, J. Phys. Chem. B, 2009, 113, 2815-2825.

10 K. R. J. Lovelock, Phys. Chem. Chem. Phys., 2012, 14, 5071-5089.

11 J. H. Santos, F. A. e Silva, S. P. M. Ventura, J. A. P. Coutinho, R. L. de Souza, C. M. F. Soares and Á. S. Lima, Biotechnol. Prog., 2015, 31, 70-77.

12 F. A. e Silva, T. Sintra, S. P. M. Ventura and J. A. P. Coutinho, Sep. Purif. Technol., 2014, 122, 315-322.

13 J. F. B. Pereira, L. P. N. Rebelo, R. D. Rogers, J. A. P. Coutinho and M. G. Freire, Phys. Chem. Chem. Phys., 2013, 15, 19580-19583.

14 S. Shahriari, C. M. S. S. Neves, M. G. Freire and J. A. P. Coutinho, J. Phys. Chem. B, 2012, 116, 7252-7258.

15 K. G. João, L. C. Tomé, M. Isik, D. Mecerreyes and I. M. Marrucho, Phys. Chem. Chem. Phys., 2015, 17, 27462-27472.

16 L. I. N. Tomé, J. F. B. Pereira, R. D. Rogers, M. G. Freire, J. R. B. Gomes and J. A. P. Coutinho, Phys. Chem. Chem. Phys., 2014, 16, 2271-2274.

17 J. F. B. Pereira, K. A. Kurnia, O. A. Cojocaru, G. Gurau, L. P. N. Rebelo, R. D. Rogers, M. G. Freire and J. A. P. Coutinho, Phys. Chem. Chem. Phys., 2014, 16, 5723-5731.

18 J. C. Merchuk, B. A. Andrews and J. A. Asenjo, J. Chromatogr. B: Biomed. Sci. Appl., 1998, 711, 285-293.

19 M. T. Zafarani-Moattar and S. Hamzehzadeh, J. Chem. Eng. Data, 2010, 55, 1598-1610.

20 M. T. Zafarani-Moattar and S. Hamzehzadeh, Fluid Phase Equilib., 2011, 304, 110-120.

21 M. T. Zafarani-Moattar and S. Hamzehzadeh, J. Chem. Eng. Data, 2009, 54, 833-841.

22 Z. Li, Y. Pei, L. Liu and J. Wang, J. Chem. Thermodyn., 2010, 42, 932-937.

23 Y. Pei, J. Wang, L. Liu, K. Wu and Y. Zhao, J. Chem. Eng. Data, 2007, 52, 2026-2031.

24 Y. Zhang, S. Zhang, Y. Chen and J. Zhang, Fluid Phase Equilib., 2007, 257, 173-176.

25 W. D. Bancroft and S. S. Hubard, J. Am. Chem. Soc., 1942, 64, 347-353.

26 C. Yu, J. Han, S. Hu, Y. Yan and Y. Li, J. Chem. Eng. Data, 2011, 56, 3577-3584.
27 F. J. Deive, M. A. Rivas and A. Rodríguez, J. Chem. Thermodyn., 2011, 43, 1153-1158.

28 J. Han, Y. Wang, Y. Li, C. Yu and Y. Yan, J. Chem. Eng. Data, 2011, 56, 3679-3687.

29 Y. Chen and S. Zhang, J. Chem. Eng. Data, 2010, 55, 278-282.

30 Y. Chen, Y. Meng, S. Zhang, Y. Zhang, X. Liu and J. Yang, J. Chem. Eng. Data, 2010, 55, 3612-3616.

31 D. Othmer and P. Tobias, Ind. Eng. Chem., 1942, 34, 693-696.

32 J. O. Valderrama, Ind. Eng. Chem. Res., 2003, 42, 1603-1618.

33 G. M. Kontogeorgis and G. K. Folas, Thermodynamic Models for Industrial Applications: From Classical and Advanced Mixing Rules to Association Theories, John Wiley \& Sons, Ltd, Chichester, UK, 2010.

34 Y. Huang, X. Zhang, Y. Zhao, S. Zeng, H. Dong and S. Zhang, Phys. Chem. Chem. Phys., 2015, 17, 26918-26929.

35 C. Held, T. Reschke, S. Mohammad, A. Luza and G. Sadowski, Chem. Eng. Res. Des., 2014, 92, 2884-2897.

36 C. Held, T. Reschke, R. Müller, W. Kunz and G. Sadowski, J. Chem. Thermodyn., 2014, 68, 1-12.

37 C. Held, A. Prinz, V. Wallmeyer and G. Sadowski, Chem. Eng. Sci., 2012, 68, 328-339.

38 C. Held and G. Sadowski, Fluid Phase Equilib., 2009, 279, 141-148.

39 C. Held, L. F. Cameretti and G. Sadowski, Fluid Phase Equilib., 2008, 270, 87-96.

40 M. C. Kroon, E. K. Karakatsani, I. G. Economou, G.-J. Witkamp and C. J. Peters, J. Phys. Chem. B, 2006, 110, 9262-9269.

41 J. S. Andreu and L. F. Vega, J. Phys. Chem. C, 2007, 111, 16028-16034.

42 X. Ji and H. Adidharma, Chem. Eng. Sci., 2009, 64, 1985-1992.

43 A. Nann, C. Held and G. Sadowski, Ind. Eng. Chem. Res., 2013, 52, 18472-18481.

44 A. Nann, J. Mündges, C. Held, S. P. Verevkin and G. Sadowski, J. Phys. Chem. B, 2013, 117, 3173-3185.

45 H. Passos, I. Khan, F. Mutelet, M. B. Oliveira, P. J. Carvalho, L. M. N. B. F. Santos, C. Held, G. Sadowski, M. G. Freire and J. A. P. Coutinho, Ind. Eng. Chem. Res., 2014, 53, 3737-3748.

46 I. Rodríguez-Palmeiro, O. Rodríguez, A. Soto and C. Held, Phys. Chem. Chem. Phys., 2015, 17, 1800-1810.

47 X. Ji, C. Held and G. Sadowski, Fluid Phase Equilib., 2012, 335, 64-73.

48 X. Ji, C. Held and G. Sadowski, Fluid Phase Equilib., 2014, 363, 59-65.

49 A. Klamt, J. Phys. Chem., 1995, 99, 2224-2235.

50 A. Klamt, COSMO-RS from quantum chemistry to fluid phase thermodynamics and drug design, Elsevier, Amsterdam, Boston, 2005.

51 A. Klamt and G. Schuurmann, J. Chem. Soc., Perkin Trans. 2, 1993, 799-805.

52 M. G. Freire, L. M. N. B. F. Santos, I. M. Marrucho and J. A. P. Coutinho, Fluid Phase Equilib., 2007, 255, 167-178.

53 M. G. Freire, S. P. M. Ventura, L. M. N. B. F. Santos, I. M. Marrucho and J. A. P. Coutinho, Fluid Phase Equilib., 2008, 268, 74-84. 
54 A. R. Ferreira, M. G. Freire, J. C. Ribeiro, F. M. Lopes, J. G. Crespo and J. A. P. Coutinho, Ind. Eng. Chem. Res., 2012, 51, 3483-3507.

55 M. G. Freire, C. M. S. S. Neves, K. Shimizu, C. E. S. Bernardes, I. M. Marrucho, J. A. P. Coutinho, J. N. Canongia Lopes and L. P. N. Rebelo, J. Phys. Chem. B, 2010, 114, 15925-15934.

56 J. Gross and G. Sadowski, Ind. Eng. Chem. Res., 2001, 40, 1244-1260.

57 J. Gross and G. Sadowski, Ind. Eng. Chem. Res., 2002, 41, 5510-5515.

58 L. F. Cameretti, G. Sadowski and J. M. Mollerup, Ind. Eng. Chem. Res., 2005, 44, 3355-3362.

59 T. Reschke, C. Brandenbusch and G. Sadowski, Fluid Phase Equilib., 2014, 368, 91-103.
60 L. F. Cameretti and G. Sadowski, Chem. Eng. Process., 2008, 47, 1018-1025.

61 D. Fuchs, J. Fischer, F. Tumakaka and G. Sadowski, Ind. Eng. Chem. Res., 2006, 45, 6578-6584.

62 D. Voet, J. G. Voet and C. W. Pratt, Fundamentals of Biochemistry, John Wiley \& Sons, Inc., New York, 1999.

63 F. Hofmeister, Arch. Exp. Pathol. Pharmakol., 1888, 24, 247-260.

64 K. A. Kurnia, M. G. Freire and J. A. P. Coutinho, J. Phys. Chem. B, 2014, 118, 297-308.

65 T. Reschke, C. Brandenbusch and G. Sadowski, Fluid Phase Equilib., 2014, 375, 306-315.

66 C. Wang, Y. D. Lei, S. Endo and F. Wania, Environ. Sci. Technol., 2014, 48, 13238-13245. 